\title{
ELECTROCORTICAL REACTIONS ASSOCIATED WITH CONDITIONED FLEXION REFLEXES ${ }^{1}$
}

\author{
Edward C. Beck, Ph.D., Robert W. Doty, Ph.D. \\ and KenNeth A. Kooi, M.D. \\ Clinical Psychology and Neurology Services, Veterans Administration Hospital, \\ Fort Douglas Division, \\ Neurology Section, Department of Psychiatry, University of Utah, \\ Salt Lake City, Utah and Department of Physiology, University of Michigan, \\ Ann Arbor, Mich.
}

(Received for publication: August 29, 1957)

The specific neural actions underlying Pavlovian conditioning are entirely unknown. Likely to play an important role in the future elucidation of such neural correlates is the recording of the electrical activity of the brain during the formation and performance of various conditioned reflexes (CR). Evidence that blocking of the alpha rhythm can be "conditioned" has been recently reviewed and greatly extended by Morrell and Jasper (1956) and summarized by Ellingson (1956). Gastaut et al. (1957) have demonstrated localized electroencephalographic effects correlated with anticipatory motor reactions in man. There are also brief reports (Galambos, Sheatz and Vernier 1956 ; Jouvet, Benoit and Courjon 1956) that potentials evoked by auditory stimuli increase in amplitude and distribution after pairing with nociceptive stimulation. Both the EEG blocking and evoked potential reactions have features similar to more usual forms of conditioned reflexes in showing extinction, differentiation, etc., and may ultimately prove to be of interest in studying mechanisms of behavioral conditioning.

There are formal objections, however, to immediately relating these electrical phenomena to conditioned reflexes. First, they are elicited by the "conditional stimulus"

1 This research was initiated on funds provided by United Cerebral Palsy Association, Inc. and subsequently supported by the Veterans Administration and a research grant (B-938) from the National Institute of Neurological Diseases and Blindness of the National Institutes of Health, Public Health Service. when it is first presented, a phenomenon never seen in the usual conditioning situation; indeed a fact which is literally contrary to the concept of conditioning. The electrocortical CR also tends to disappear despite continued reinforcement and even the UR may vanish with repeated presentation of the US (e.g. Gastaut et al. 1957). Finally there is a paucity of data relating these electrical events to learned behavior.

Motokawa and Huzimori (1949) have reported that a transitory blocking of the alpha rhythm to tonal CS appears in man to precede and accompany formation of a conditioned galvanic skin response. The experiments of Popov (1946-47) show that electrical effects, which are probably EEG arousal reactions, precede or accompany formation of conditioned respiratory or escape reactions in the rabbit. However, attention was directed mostly to the electrocortical events, and their correlation with the motor manifestations of conditioning is not always clear. Artem'yev and Bezladnova (1952) have specifically looked for such a correlation. Using shock to hindleg as an unconditional stimulus (US) and tone as CS they noted that a $75 \mu \mathrm{V}$. "on" type potential was consistently evoked in the cat's cortex by the CS for some time prior to the formation of flexion CRs. While the initial rarity of evocation of potentials by their CS is a little puzzling and perhaps related to variations in electrode replacement at each training session, their results on ten cats are reported as consistent and may indicate such changes, as also recorded by Ga- 
lambos et al. (1956) and Jouvet et al. (1956), do actually correlate with learned somatic behavior. The findings of Buser and Rougeul (1957) that antecedent stimulation in one sensory modality augments potentials evoked by stimulation of a second modality raises many possibilities for electrophysiological studies of CS-US combinations, but also indicates such alterations are fairly non-specific and not necessarily limited to conditioned reflex formation. Chow, Dement and John (1957) have specifically shown that certain "conditioned" electrocortical patterns need have no immediate behavioral significance.

These problems have now been carefully defined and examined by Ricci, Doane and Jasper (1957). In a series of extremely well controlled experiments they have shown that many of the phenomena of "electrocortical conditioning" have no apparent significance to or in some instances are negatively correlated with the conditioning of a motor response, and have clearly illustrated certain fallacies in inferences made on the basis of surface records alone. On the other hand, they confirm the general impression, elaborated herein, that EEG arousal reactions to the CS invariably become consistent before any somatic signs of conditioning appear.

Such study of arousal reactions is frequently handicapped by the persistence of low voltage, fast (LVF) EEG patterns in the alert subject so that the observed changes in pattern may be equivocal. During experiments on the conditioning of cats immobilized with bulbocapnine (Beck and Doty 1957) it was noted that this drug usually produces slow EEG patterns which permit ready detection of any transition to the LVF activity concomitant to arousal. Since bulbocapnine appears to have no effect on the readiness with which flexion CRs are established, it provides the opportunity for observing systematically the correlation between conditioning and electrical reactions to the CS.

\section{METHOD}

Cats were prepared with permanently fixated electrodes overlying posterior cruciate, mid-marginal, and middle ectosylvian gyri with reference electrodes in frontal sinus or parietal bone just rostral to the lambdoidal suture. Stainless steel serews $1.3 \mathrm{~mm}$. in diameter and $2.4 \mathrm{~mm}$. long were screwed into the bone to rest upon the dura mater. The lead wires were joined and insulated at the screws by cold-cure acrylic plastic retained in a ring cut from polyethylene tubing. Lead wires were brought individually through the skin after several centimeters passage through muscle to limit the degree of their flexion.

Bulbocapnine hydrochloride, $15-50 \mathrm{mg} / \mathrm{kg}$., was administered intramuscularly. Doses used in later experiments were sufficiently low $(15-25 \mathrm{mg} / \mathrm{kg}$.) that the animals made slight flexion CRs while drugged; but to be certain that depression of motor activity by the drug was not biasing the results, all animals were tested for flexion CRs in the undrugged state prior to each training session.

A $700 /$ sec. tone enduring 2 sec. served as CS, and the US, a brief 20-45 V. unavoidable shock to the toes, overlapped its termination. The CS-US combination could be presented automatically every 30 sec. or administered at random, chosen intervals. The animals rested in a hammock and when undrugged were gently restrained by rubbercovered ropes about the pelvic and pectoral girdles. An eight-channel Grass model III-C electroencephalograph was used for recording. The EKG was taken from contralateral fore and hindlimbs. Respiration was recorded from a sphygmomanometer cuff enveloping the animal and leading to a Statham $0-5 \mathrm{~cm}$. $\mathrm{Hg}$. pressure transducer and Grass balance demodulator. Flexion CRs were registered from a small clamp binding the pertinent limb through a weak spring to a Grass $20 \mathrm{~kg}$. force-displacement transducer and balance demodulator, or as the electromyogram taken from needles in the semitendinosus muscle. Sometimes, and especially with undrugged animals, limb movements were merely observed, in which case a CR was counted only if a discrete flexion of the appropriate limb exceeding $1.5 \mathrm{~cm}$. excursion occurred to the CS prior to or without administration of the US.

The drugged cats were habituated to the CS until no EEG changes were observed to 
the onset of the tone for at least five successive presentations. This occurred within 9 to 45 trials, averaging 21 (table I). On one cat, not included in table $\mathrm{I}$, it was noted habituation to a $500 /$ sec. tone was obtained after 15 presentations, the next 5 giving no EEG arousal. Then $700 / \mathrm{sec}$. for 8 presentations induced arousal only on the first 3 , and 5 presentations each of 1000 and 2000/sec. failed to produce any arousal. There thus appears to be considerable generalization of obvious as to be immediately detected even when the trace signaling the CS was covered. (2) Definitely no change; this required presence of a sufficiently high, slow background pattern that a transition to LVF activity would be unmistakable. (3) Equivocal; an evaluation reflecting either uncertainty as to change or the continuous presence of LVF activity which precluded the detection of any change towards arousal. There was complete agreement among the three evaluators over 80

TABLE I

SUMMARY OF EXPERIMENTS

\begin{tabular}{|c|c|c|c|c|c|c|c|c|}
\hline \multirow[b]{2}{*}{ Animal } & \multirow{2}{*}{$\begin{array}{l}\text { Presenta- } \\
\text { tions to } \\
\text { habituate }\end{array}$} & \multirow{2}{*}{$\begin{array}{l}\text { Training } \\
\text { sessions }\end{array}$} & \multicolumn{2}{|c|}{ LVF" CRs" } & \multicolumn{2}{|c|}{$\begin{array}{c}\text { Respiratory } \\
\text { CRs }\end{array}$} & \multicolumn{2}{|c|}{ Flexion CRs } \\
\hline & & & Ist & $80 \% 1$ & $1 \mathrm{st}$ & $80 \% 1$ & $1 s t$ & $80 \% 1$ \\
\hline 1 & 6 & 9 & 2 & 83 & 199 & 274 & 324 & 380 \\
\hline $2^{*}$ & 4 & 11 & 6 & 450 & 187 & Never & Never & \\
\hline 3 & 4 & 13 & 73 & 619 & Never & Never & 627 & 671 \\
\hline 5 & 23 & 6 & 9 & 81 & 54 & 98 & 118 & 174 \\
\hline 6 & 14 & 5 & 4 & $144^{* *}$ & 35 & $79 * *$ & 128 & 167 \\
\hline $7+$ & 28 & 1 & 3 & 42 & _. & - & - & - \\
\hline 8 & 15 & 6 & 2 & 79 & 103 & Never & 159 & 210 \\
\hline 9 & 9 & 5 & 16 & 107 & 121 & 168 & 121 & 169 \\
\hline
\end{tabular}

1 Trials up to but not including the performance of 8 or $16 \mathrm{CRs}$ in 10 or 20 presentations, all for tonal CS.

* Animal died after 514 trials.

* Persistent LVF activity despite bulbocapnine made many trials "equivocal" so that the seeming lag of $\mathrm{LVF}$ "CRs" over respiratory CRs is not considered significant.

+ Only LVF reactions were studied in this animal and were "conditioned" and "extinguished" in a single, protracted training session.

the effects of habituation. The first few animals were habituated for as many as 100 presentations given on several days. Since no significant lessening of the habituated condition was noted from day to day in these animals and since "habituation" during the first trials seems to occur in most animals even when the CS is paired with the shock, training was begun in the later experiments during the same session in which habituation was established. Pairing of the US with the CS was given in sessions of 25-50 trials per day. Continuous records were taken during the entire training. All records were subjected to completely independent analysis by the three experimenters. The EEG changes to CS presentation were scored as: (1) Transition to or increase in LVF activity which was so per cent of the time. Agreement between two of the three investigators was accepted as identifying the response.

\section{RESULTS}

Prior to the injection of bulbocapnine the basic EEG pattern usually consisted of low amplitude, 20-40/sec. activity (fig. 2b). Under the influence of the drug the animals remained quiet with their eyes open and displayed moderate catalepsy. In this state the EEG characteristically consisted of waves of irregular frequency at about $100 \mu \mathrm{V}$. intermixed with bursts of $5-8 /$ sec. activity attaining $200 \mu \mathrm{V}$. (fig. 1, 2, 4, 6, 7). Such patterns are similar to those described by Hess, Koella and Akert (1953) as being associated with a state of rest and relaxation. In one animal (table $I$, 


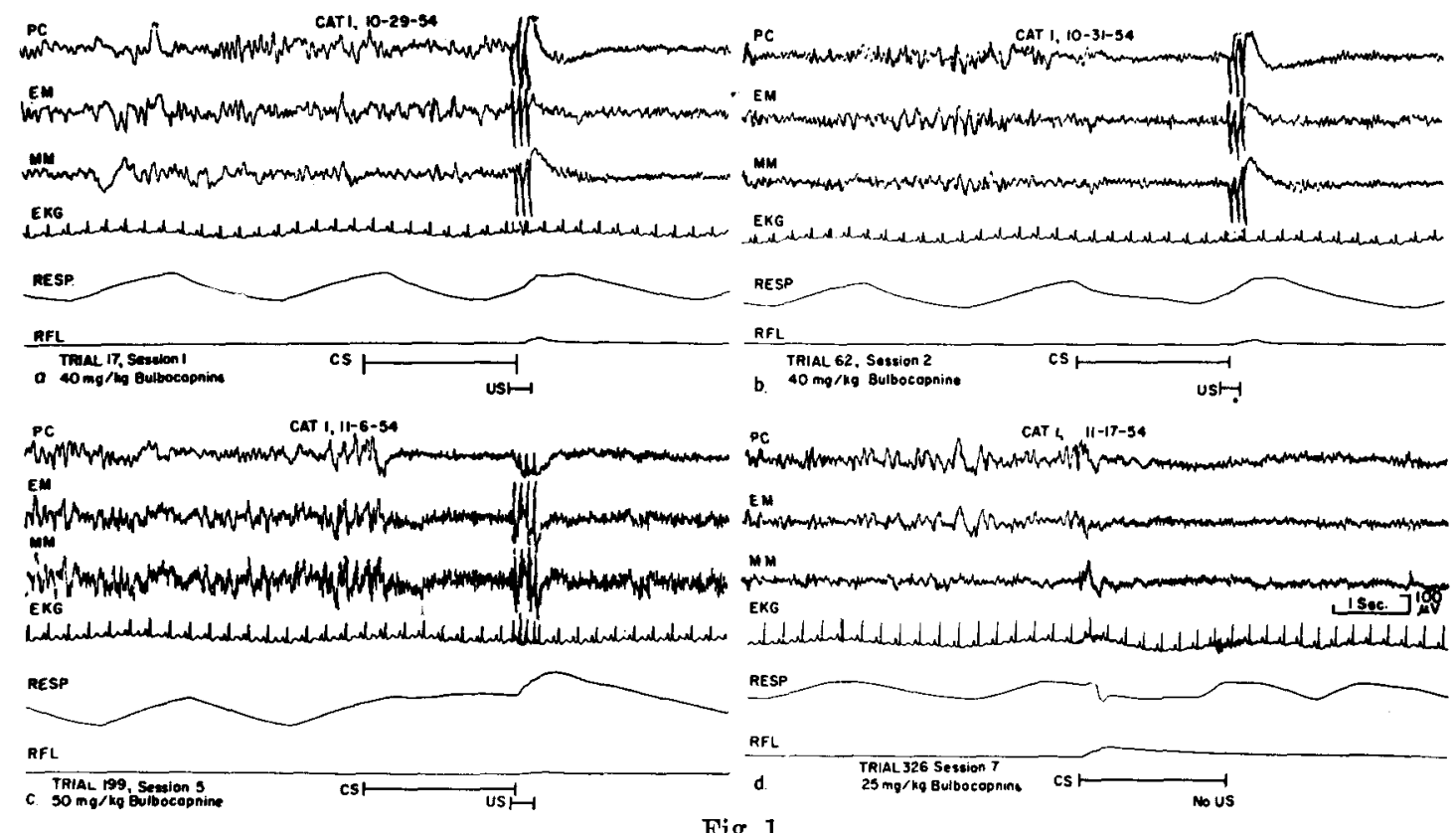

Fig. 1

Progression of conditioning: (a) trial 17, first training session in which transition to LVF activity occurred to the US; (b) trial 62, second training session, LVF activity oceurred to $\mathrm{CS}$ but is the only sign of conditioning; (c) trial 199, fifth training session, typical of more intensive LVF activity to CS at this stage; note respiratory $\mathrm{CR}$ which is the first occurrence of any somatic CR in this animal; $(d)$ trial 326 , seventh training session, in which flexion CRs appeared for the first time in the tests made prior to giving bulbocapnine. A lower dose was then employed to permit their further observation.

The following abbreviations have been used for this and other figures: PC-posterior cruciate gyrus; EM-middle ectosylvian gyrus; MM-middle of marginal gyrus; reference electrodes were in frontal sinus unless otherwise designated. EKG-cardiae rate; RESP-respiration, inspiration denoted by upstroke; RFL-, RHL-, or RST-, movement of right foreleg, right hindleg, or the electromyogram of right semitendinosus muscle, in each case the conditioned limb. The EEG has been recorded from the hemisphere ipsilateral to the conditioned limb in all figures except figures 6 and 7 , although many contralateral recordings were made on other animals.

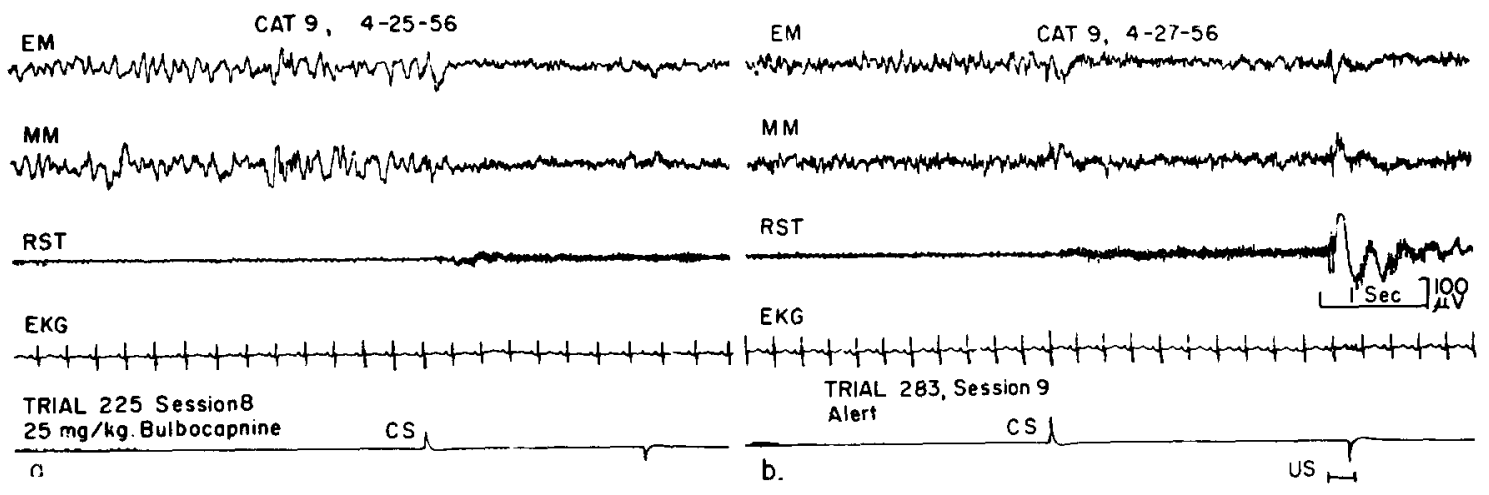

Fig. 2

Conditioned responses: (a) when under the influence of bulbocapnine, and (b) when not drugged; change to LVF accompanying the CR can be seen in both instances. 
cat $\# 4$ ), the drug failed to produce the higher amplitude pattern and LVF activity continued throughout the conditioning trials.

Almost immediately after the US was paired with the CS, the previously habituated animals began to show electrocortical arousal

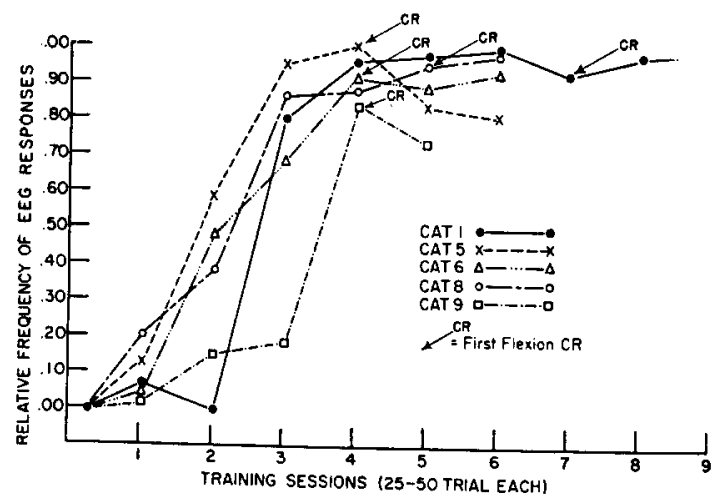

Fig. 3

Summary of frequency of LVF reactions to CS with progression of training; arrows indicate point in training where conditioned flexions were first observed, while terminal point on each curve indicates criterion of $8 / 10$ conditioned flexions had been reached. A LVF response was not counted here whenever there was either a definite lack of alteration or the alterations were equivocal (see METHOD). Equivocal alterations averaged 15 per cent with a range of 0 to 40 per cent.

to the CS alone, as summarized in table I. In the first and second training sessions, however, such electrical responses were infrequent in occurrence (fig. 3), and it was more usual for the animal to be aroused only by the US as exemplified in figures 1 and 4 . Such arousal usually endured about 5-20 sec. in animals under bulbocapnine if the US was kept at moderate intensity. Usually by the third training session the cats showed EEG arousal to the CS 80 per cent of the time, although there was great variability among individuals (table I). In all cases the electrical arousal reactions to the CS became consistent for some time before any other sign of conditioning appeared (table $I$, fig. 3 ). In one cat, \#7, these electrical responses were "conditioned" to an 80 per cent level, then completely extinguished. Subsequent testing yielded no somatic CRs. The LVF patterns evoked by the CS became more definite with progression of conditioning and this was evidenced by more complete agreement among the separate analyses of the three investigators. A qualitative difference between LVF patterns in earlier and later training sessions can be observed in figure 1 . This change or intensification in the LVF pattern seemed to be a consistent occurrence, but was too variable to be rigourously defined. When the records were examined for any systematic localization of electrocortical alterations, none were encountered, although in about 50 per cent of the animals the leads were placed contralateral to the conditioned limb. The LVF activity was most readily discernable in the frontal leads and could always be seen there if it appeared anywhere.

Other electrocortical responses to the CS were identifiable in certain animals. A rhythmic 16-18/sec. pattern of moderately high amplitude localized at the frontal leads was particularly prominent in cat $\# 9$ (fig. 4a) and was also seen occasionally in cats 5 and 6 . This pattern was not identifiable in the pretraining records which ranged from 30 to 40 min. The relationship between this pattern and arousal reactions is illustrated in figure 5. For this one animal (eat $\# 9$ ) the $16-18 /$ sec. pattern was frequently seen in the early training sessions, disappeared when LVF reactions were consistent, and then reappeared in later sessions with overtraining. After the second training session, it was occasionally seen to occur "spontaneously" and at this time it was observed to be evoked by the CS 20 per cent of the time. By the third training session the pattern was seen as a response to the CS more than 40 per cent of the trials while no change could be observed in "spontaneous occurrences".

In three animals ( $\$ 2,3$, and 6 ) bursts of 2-4/sec. high amplitude waves (fig. 6), most prominent in marginal and ectosylvian gyri, were evoked by the CS or other auditory stimuli. Analysis showed conditioned limb flexions never occurred when the $2-4 /$ sec. pattern to the CS prevailed. Indeed, the one animal ( $\# 3$, fig. 6) that displayed such slow wave bursts to the CS most frequently (an average of 76 per cent of all trials for 12 training sessions) required more trials than 

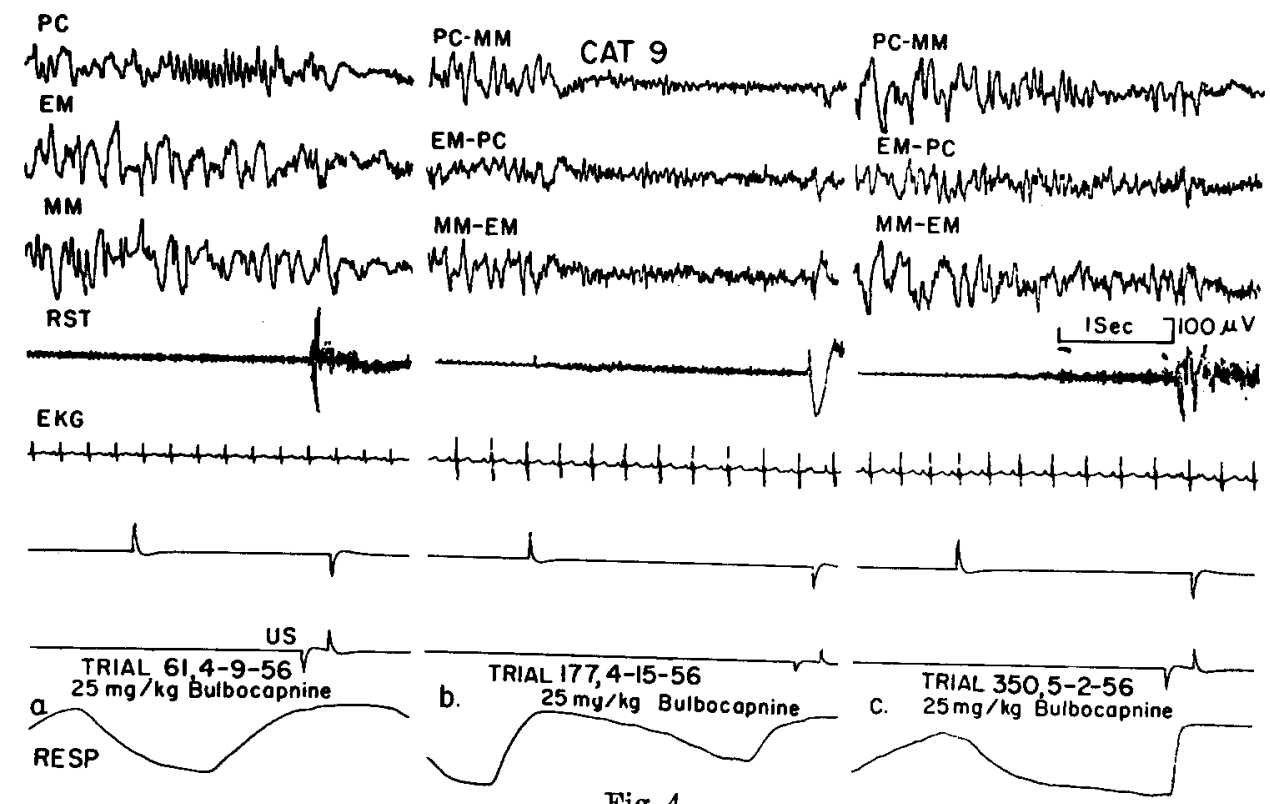

Fig. 4

Examples of responses in cat 9: (a) no reaction to CS except 17/sec. burst in frontal leads; (b) flexion and respiratory CRs both present; (c) exeellent flexion CR (no respiratory CR) during relatively slow, higher amplitude EEG.

any other cat to reach the 80 per cent criterion for limb flexion. It was not until the 13 th training session that $\mathrm{LVF}$ responses to the CS emerged with any consistency i.e., 26 of 45 trials. It was following seven consecutive occurrences of such arousal reactions in this session that the animal made its first flexion CR.

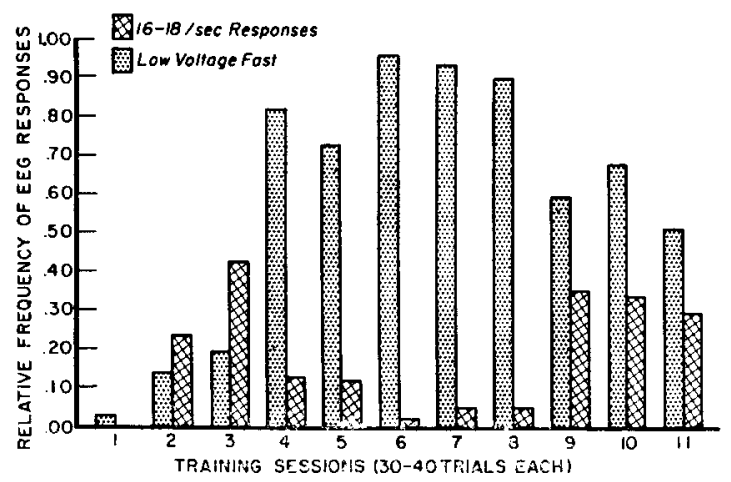

Fig. 5

Cat 9, proportion of $16-18 /$ sec., responses in frontal leads to CS compared with LVF responses during various training sessions. These responses were usually mutually exclusive, but on occasion the LVF pattern developed during the latter half of the CS. (The 16$18 / \mathrm{sec}$. response was seored as equivocal for figure 3).
The electrodes were suitably situated in 6 cats to record an evoked spike discharge at the onset of the CS. In no instance was there any correlation between these "on" responses and the course of conditioning or the occurrence of CRs. In the hope of better distinguishing such correlation, one animal ( $\$ 6)$, after being conditioned to tonal $\mathrm{CS}$, was conditioned to a series of four clicks with the US accompanying the last click. Figure 7 shows typical records from this cat in which a relatively fast EEG was present under bulbocapnine but in which a slight transition to a still faster pattern could be consistently detected in the frontal leads to the first click. The potentials evoked by the clicks, on the other hand, vary with no set pattern in their amplitude.

As EEG arousal responses became more consistent, respiratory CRs usually began to appear. As illustrated in figures 1 and 7 , they were very irregular in form, most frequently consisting of added inspiratory effort or breath holding. Any interruption of the respiratory rhythm accompanying the CS was counted as a respiratory CR. They were seen at some time during the course of training in most animals, but unlike the electrical 
and flexion CRs, failed to appear consistenly in many instances (table I).

No conditioning of the cardiac cycle was seen in these experiments even when recorded without bulbocapnine.

During the course of conditioning and for some time after CRs were first fully establish- (see fig. 8). One of these eats, $\sharp 9$, had flexion CRs 100 per cent of the time after 237 trials, and was then subjected to 183 additional training trials to a total of 420 trials in 11 sessions. During this training, in addition to bulbocapnine, chlorpromazine (4-9 $\mathrm{mg} / \mathrm{kg}$.) or Nembutal $(\mathbf{1 0 . 1 5} \mathrm{mg} / \mathrm{kg}$.) were sometimes

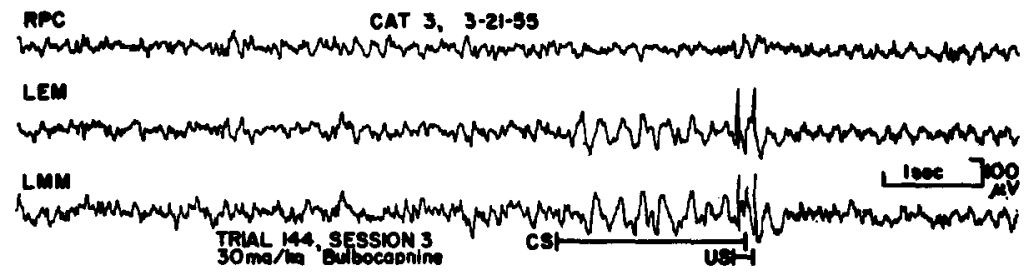

Fig. 6

Bursts of high voltage $2-4 /$ sec. activity evoked by CS in cat 3 .

ed, respiratory or flexion CRs never appeared unless LVF activity was present. It is of considerable interest to know whether a learned response can ever appear in the absence of LVF patterns. Training in three animals ( $\# 5,6$, and 9) was continued for given to enhance slower EEG patterns. Analysis of the data so obtained indicates that if $3-6 /$ sec. waves persisted throughout the period of the CS, flexion or respiratory CRs did not occur. In rare instances, however, flexion CRs appeared during relatively slow,

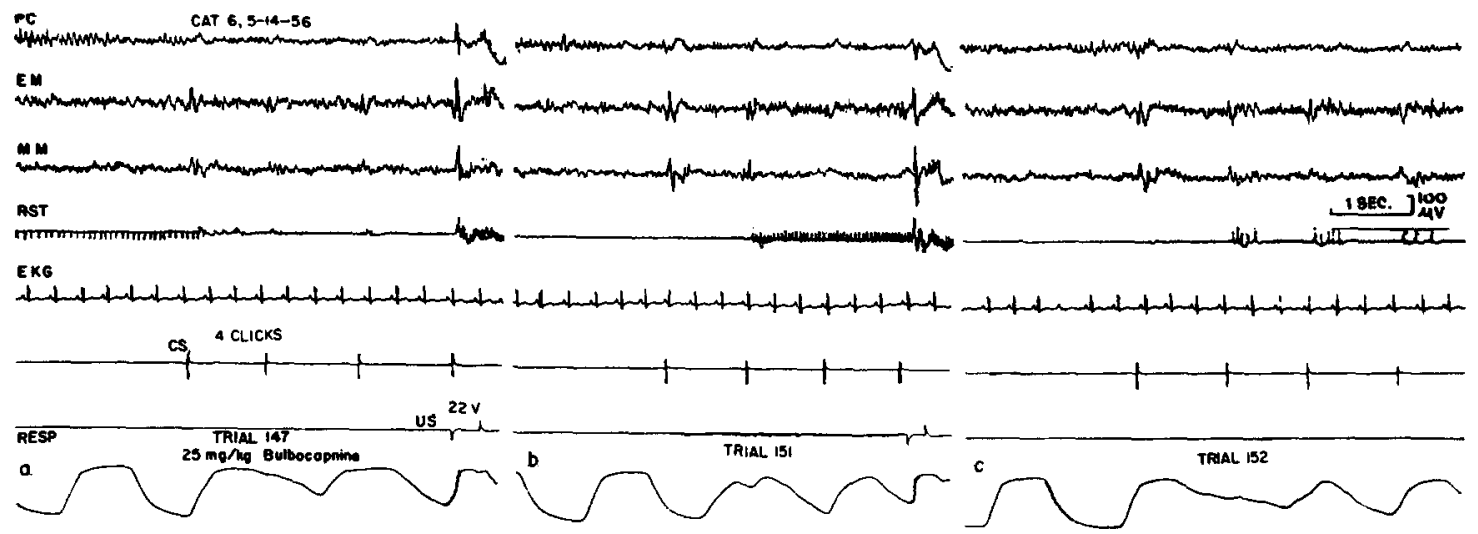

Fig. 7

Examples of potentials evoked by click stimuli serving as CS, taken during a single training session. The trial numbers are for click CS and hence are in addition to this animal's previous training using tonal CS. Note variations in potentials evoked in ectosylvian and marginal gyrus leads, and in the respiratory CRs, as well as the conditioned responses of what are probably single units of right semitendinosus muscle. Brief auditory stimuli evoked potentials from the marginal gyrus leads prior to any conditioning procedure.

some time after the 80 per cent level of flexion CRs had been attained. In all three there appeared to be a progressive diminution in the "intensity" of the LVF electrocortical response to the $\mathrm{CS}$, so that a larger proportion of these responses were judged as "equivocal" high amplitude activity. Records of this sort are presented in figures 4 and 9 . In the few other records of CRs during slow activity, the frontal leads generally show a frequency of at least $12 /$ sec., with the $4-6 /$ sec. action prevailing at more posterior leads. 
Electrocortical CRs thus show a tendency towards "extinction" even though reinforcement and the somatic CRs continue. When shortly after flexion CRs were established at

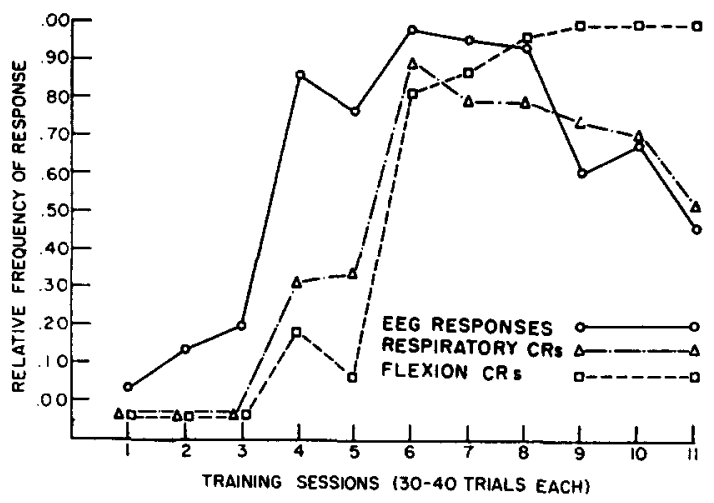

Fig. 8

Cat 9. Diminution in percentage of LVF reactions to $\mathrm{CS}$ and of respiratory CRs during protracted overtraining in which flexion CRs were maintained at 100 per cent level.

the 80 per cent level the US was with-held so that the CS was not reinforced, i.e., the procedure of extinction, the somatic CRs were abolished much sooner than the electrocortical with the findings of Popov (1946-47) quoted below can be made. In the few extinction experiments performed, slow, high amplitude EEG reactions appeared occasionally as a response to the CS and this also occurred when the animals were subjected to excessively long sessions of training. Such responses so far have not appeared sufficiently consistent to warrant their association with states of "internal inhibition", but this possibility is by no means excluded.

\section{DISCUSSION}

That EEG arousal reactions to the CS precede in their formation and accompany somatic CRs is unequivocal in these experiments. The significance of this fact remains to be evaluated.

It is possible that the level or type of neural action of which $\mathrm{LVF}$ patterns are a crude measure is an essential correlate of the conditioning process. There is certainly no unassailable evidence that conditioning can ever occur while a high voltage, slow EEG prevails as during sleep or under the influence of nareotics; while it is common knowledge

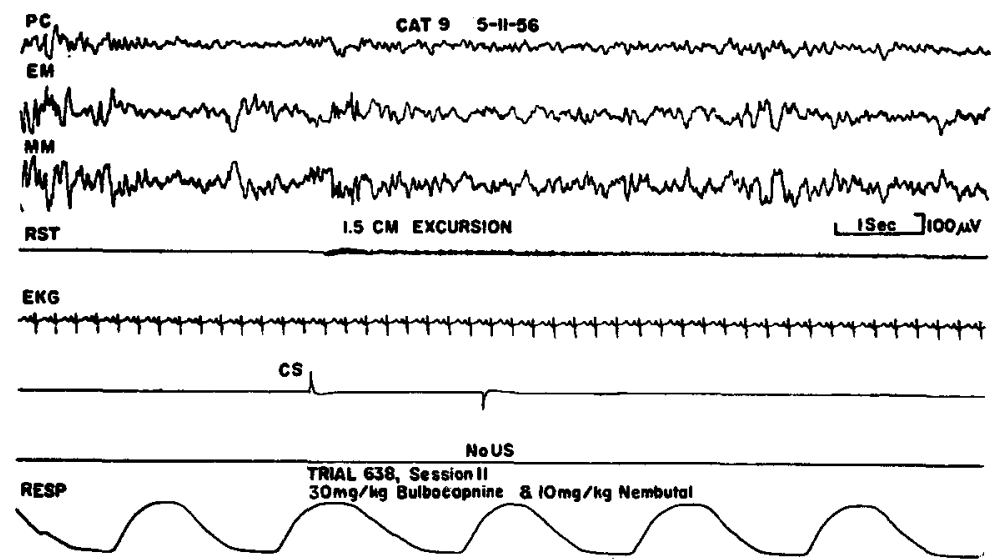

Fig. 9

A conditioned leg flexion of about $1.5 \mathrm{~cm}$. excursion recorded with minimal disturbance of slow EEG patterns by the CS.

reaction to the CS. The latter reaction was extinguished, however, and upon reconditioning its reappearance preceded the development of somatic CRs. The phenomena of extinction were not extensively examined so no general statement nor meaningful comparison that learning and performance tend to diminish with the recession or disturbance of faster EEG patterns (see, for example, Simon and Emmons 1956; Kooi and Hovey 1957). On the other hand, this relation is not absolute since a few patients can accurately retain or 
sometimes follow verbal instruction during the bizarre electrical patterns of petit mal (e.g., Kooi and Hovey 1957; Jung, 1954), or even maintain excellent intellectual function during persistent, generalized 3/sec. rhythms (Gastaut 1954). Behavioral arousal without concomitant blocking of slow electrocortical patterns has also been observed following brain stem lesions (Doty and Beck, to be published) and in cats under the influence of atropine (Elkes, Elkes and Bradley 1954). Under the latter circumstances respiratory CRs can occur without LVF action (Beck, unpublished).

It is also most necessary to emphasize, as made decisively clear in the experiments of Ricci, Doane and Jasper (1957), that the surface EEG is not necessarily an accurate or easily interpreted reflection of the activity of subjacent neurons. Thus there seems little doubt that highly significant neural activity could continue without electrical detection at the macroscopic level.

It may also be necessary in considering these phenomena to separate the process of training or acquisition of a learned act from mere performance, i.e. it is probable that learning in most cases cannot occur without associated LVF action, but that once the learned action is thoroughly established, it may proceed without widespread transition to faster electrocortical patterns. The evidence presented on these points is hardly decisive but is at least consonant with this supposition. Thus eat \#4 (table I) in which flexion CRs were established most readily had such a consistently fast EEG that arousal reactions could not be reliably detected; whereas cat $\# 3$, in which the CS elicited peculiar high amplitude slow waves (fig. 6 ), and $\sharp 2$, in which arousal reactions to the CS did not become consistent for hundreds of trials, were both extraordinarily slow in showing flexion CRs. With overtraining flexion $\mathrm{CRs}$ can continue at a high level (100 per cent in cat $\# 9$ ) while the EEG arousal reactions diminish (fig. 4, 8 and 9). A similar effect was noted by Popov (1946-47, p. 104) in extinguishing defensive CRs to tonal CS: "A près 22 répétitions isolées du son, le réflexe conditionné respiratoire était encore bien exprimé mais le réflexe conditionné électrocortical avait disparu.',

If the conditional electrocortical reactions become relatively localized with progression of training, as reported for certain experimental situations (Gastaut et al. 1957 ; Morrell and Jasper 1956; Jouvet et al. 1956), there is a further chance the significant electrical reaction could go undetected. In such case the foregoing examples of somatic CRs without apparent electrocortical CRs would merely reflect this progressive localization of the neural processes and failure to place electrodes in the appropriate cortical areas; but such assumption is obviously gratuitous in the present instance. While the EEG arousal reactions in the overtrained cats were occasionally limited to the frontal leads and were always most prominent there, this cannot yet be interpreted as evidence for localization of effect (although it is exactly concordant with the expectations of Gastaut et al. 1957) since there is a distinct tendency for reactions in the frontal areas of the cat to be most prominent for any manner of arousal (e.g. Moruzzi and Magoun 1949).

The failure to find a correlation between magnitude and distribution of spike potentials evoked by the CS and the appearance of somatic CRs may also be the result of unfavorable electrode placement or other technicalities such as use of drugged animals. There is an equal likelihood, however, that this failure is significant and demonstrates the evoked potential phenomena are not closely related to the process of conditioning. The latter conclusion would certainly be more compatible with the observation of Ricci, Doane and Jasper (1957) that evoked potentials diminish whenever a motor CR is actually performed.

\section{SUMMARY}

Cats with permanently implanted cortical electrodes were drugged with bulbocapnine and the EEG recorded continuously during the formation of flexion conditioned reflexes (CR). The drug has no readily detectable effect on rate of conditioning and usually produces such slow EEG patterns that electro- 
cortical arousal reactions are well demarcated. Arousal reactions to a tonal conditional stimulus (CS) given alone soon cease to occur, but become more frequent as the CS is paired with an unavoidable shock to the leg 25-50 times a day over several days. In all cases the EEG reactions attain a high level of consistency before the first respiratory or flexion CRs appear, almost invariably accompany them, and can survive for some time after these somatic CRs are fully extinguished. There is a tendency, however, for the EEG arousal response to diminish with overtraining despite continuation of somatic CRs and shock reinforcement, and in certain instances somatic CRs can occur during relatively slow electrocortical activity. There was no evidence that the somatic $\mathrm{CRs}$ correlated with any localization of electrocortical reactions or alterations of cortical evoked potentials.

\section{RÉSUMÉ}

Des chats porteurs d'électrodes corticales implantées à demeure ont été drogués avec de la bulbocapnine et l'électroencéphalogramme a été enregistré d'une façon continuelle pendant la formation de réflexes conditionnés en flexion (CR). La bulbocapnine n'exerce aucun effet apparent sur le développement du conditionnement et en général produit des activités lentes dans I'EEG qui rendent facile l'observation sur le tracé EEG de la réaction d'éveil qui alors d'une façon très claire apparaît et contraste avec l'activité de fond lente. Des réactions d'éveil en réponse à un stimulus conditionné sonore (CS) présenté seul cesse d'apparaître bientôt, mais deviennent de plus en plus fréquents quand le CS est combiné avec un choc électrique appliqué à la jambe 25 à 50 fois par jour pendant une période de plusieurs journées. Dans tous les cas les réactions électroencéphalographiques deviennent très constantes avant que le premier CR respiratoire ou en flexion apparaisse. Ces réactions d'éveil accompagnent les CR d'une facon presque invariable et sont capable de survivre pour un certain temps l'extinction complète de ces CR somatiques. Avec surconditionnement il $\mathrm{y}$ a cependant une tendance à une diminution des réponses d'éveil dans l'électroencéphalogramme et ceci malgré la continuation de CR somatiques et de renforcements par chocs électriques. Dans certaines circonstances des CR somatiques peuvent même se produire pendant une période d'activité électro-corticale relativement lente. Il n'y a aucune indication que les CR somatiques soient en corrélation avec une localisation spécifique de la réaction électrocorticale ou avec les altérations de potentiels évoqués corticaux.

\section{ZUSAMMENFASSUNG}

Katzen mit permanent implantierten kortikalen Elektroden erhielten Bulbokapnin. Ihr EEG wurde kontinuierlich aufgezeichnet während der Formierung bedingter FlexionsReflexe (CR). Die Droge hat keinen merklichen Einfluss auf die Geschwindigkeit, mit der bedingte Reflexe sich entwicklen und erzeugt üblicherweise langsame Hirnstromwellen, so dass elektrokortikale Weckreaktionen in klar demarkierter Weise auf der EEG-Kurve sich aufzeichnen. Weckreaktionen in Antwort auf einen akustisch bedingten Reiz (CS). verschwinden bald, wenn dieser Reiz allein gegeben wird. Diese Weckreaktionen werden jedoch häufiger, wenn der CS gepaart wird mit einem unvermeidlichen elektrischen Schock, welcher am Bein 25 bis $50 \mathrm{Mal}$ im Tag während mehreren Tagen appliziert wird. In allen Fällen erreichen die EEG-Reaktionen einen hohen Grad von Verlässlichkeit bevor der erste bedingte Atmungs- oder Flexionsreflex erscheint. Diese EEG-Reaktionen begleiten die CR in fast regelmässiger Weise und überdauern den Zeitpunkt, an welchem somatische CR vollständig ausgelöscht sind. Die EEG Weckreaktionen haben jedoch eine Tendenz abzunehmen, wenn das Tier übertrainiert wird, und dies obwohl die somatischen CR anhalten und die Verstärkung durch Schocks weitergeführt wird. In gewissen Fällen können sogar während einer Periode von relativ langsamer Rindenaktivität somatische CR auftreten. Keine Anzeichen wurden gefunden, dass die somatische CR in irgendwelcher Beziehung stehen mit einer spezifischen Lokalisation der elektrischen Rindenantwort oder mit Veränderungen kortikaler Reizantworten. 


\section{REFERENCES}

Artem'yev, V. V. and Bezladnova, N. I. Electric reaction of the auditory area of the cortex of the cerebral hemispheres during the formation of a conditioned defense reflex. Trans. Inst. Physiol. I. P. Pavlov, Acad. Sci. USSR, 1952, vol. I, Voprosy fiziologii $i$ pathologii vyesshnay nervnoi deyatel nosti, Moscow-Leningrad, 1952, pp. $228-236$.

Beck, E. C. and Dotr, R. W. Conditioned flexion reflexes acquired during combined catalepsy and de-efferentation. J. Comp. Physiol., Psychol., 1957, $50: 211-216$.

Buser, P. and Rougeud, A. Cortical sensory responses in the cat (chronic preparation). Their modification during the establishment of temporary connections. EEG Clin. Neurophysiol., 1957, 9: 362.

Chow, K. L., Dement, W. C. and John, E. R. Conditioned electrocorticographic potentials and behavioral avoidance response in cat. $J$. Neurophysiol., 1957, 80 : 482-493.

Doty, R. W. and BECK, E. C. Effect of brain stem lesions on conditioned responses of cats. To be published.

Elkes, J., Elkes, C. and Bradlex, P. B. The effect of some drugs on the electrical activity of the brain, and on behavior. J. Ment. Sci., 1954, 100 : 125-128.

Ellingson, R. J. Brain waves and problems of psychology. Psychol. Bull., 1956, 53 : 1-34.

Galambos, R., Sheatz, G. and Vernier, V. G. Electrophysiological correlates of a conditioned response in cats. Science, 1956, $123: 376-377$.

Gastaut, H., Jus, C., Morrell, F., Storm van Leeuwen, W., Dongier, S., Naquet, R. Regis, H., Roger, A., Bekkering, D., KAMP, A. et WERRE, J. Etude topographique des réactions électroencéphalographiques conditionnées chez l'homme. EEG Clin. Neurophysiol., 1957, 9: 1-34.
GASTADT, H. Brain stem and cerebral electrogenesis in relation to conseiousness. In Brain Mechanisms and Consciousness, by E. D. Adrian, F. Bremer and H. H. Jasper. Eds. Charles C. Thomas, Publisher, Springfield, Illinois, 1954, pp, 249-279.

Hess, R., Koella, W. P. and Akert, H. Cortical and subcortical recordings in natural and artificial induced sleep in cats. EEG Clin. Neuro. physiol., 1953, 5: 75-90.

KooI, K. A. and Hover, H. B. Alterations in mental function and paroxysmal cerebral activity. Arch. Neurol. Psychiat., Chicago, 1957, 78: 264-271.

Jouvet, M., Benoit, O. et CourJon, J. Aspects EEG de la formation de liaisons temporaires dans le cerveau. Abstr. Comm. XXth Int. Physiol. Cong., 1956,475 .

Jung, R. Correlation of bioelectrical and autonomic phenomena with alterations of consciousness and arousal in man. In Brain Mechanisms and Consciousness by E. D. Adrian, F. Bremer and H. H. Jasper. Eds., Charles C. Thomas, Publisher, Springfield, Illinois, 1954, pp. 310-339.

MoRRELL, F. and JASPER, H. Electrographie studies of the formation of temporary connections in the brain. EEG Clin. Neurophysiol., 1956, 8: 201-215.

Moruzzi, G. and MAcoun, H. W. Brain stem reticular formation and activation of the EEG. EEG Clin. Neurophysiol., 1949, 1: 455-473.

MoтокаWA, K. and Huzimori, B. Electroencephalograms and conditioned reflexes. Tohoku J. Exp. Med., 1949, 50: 215-223.

Popov, N. A. Etudes électroencéphalographiques du problème des réflexes conditionnés II. Année Psychol., 1946-47, 47-48: 97-127.

Ricci, G., DoANE, B. and JASPER, H. Microelectrode studies of conditioning : technique and preliminary results. Rapports du IVe Congrès International d'EEG et de Neurophysiologie Clinique, Les Editions "Acta Medica Belgiea”', Brussels, 1957, pp. 401-415.

SImon, C. W. and EmMons, W. H. EEG, conscious. ness and sleep. Science, 1956, 124: 1066-1069.

Reference: Beck, E. C., Doty, R. W. and KooI, K. A. Electrocortical reactions assoeiated with conditioned flexion reflexes. EEG Clin. Neurophysiol., 1958, 10:279-289. 